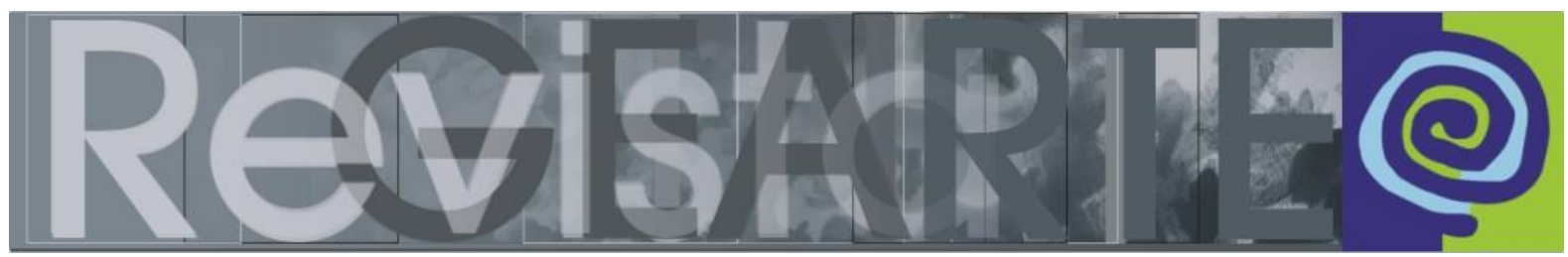

e-ISSN 2357-9854

\title{
Do que falamos quando falamos de uma educação artística de qualidade: 0 caso chileno
}

\author{
Leonardo Verde Charréu (Instituto Politécnico de Lisboa — IPL, Lisboa, Portugal) \\ Madalena Campos Ghira (Instituto Politécnico de Lisboa — IPL, Lisboa, Portugal)
}

\begin{abstract}
RESUMO - Do que falamos quando falamos de uma educação artística de qualidade: o caso chileno - Desenvolvido a partir de um trabalho de pesquisa para uma disciplina do mestrado em educação artística ministrado na Escola Superior de Educação do Instituto Politécnico de Lisboa, Portugal, o presente trabalho busca analisar uma publicação de apoio ao Plano Nacional de Artes na Educação que está sendo desenvolvido na atual reforma educativa chilena. Utilizado como "material de aula", o caderno analisado possui os eixos que estruturam uma intencionalidade educativa que nos parece bastante pertinente e merecedora de estudo e destaque. Como muitos dos problemas da educação artística contemporânea, em particular a falta de uma clara intencionalidade educativa, parecem ser transversais a muitos países, o trabalho desenvolvido no Chile pode constituir uma referência não só para a justificativa da presença das artes no currículo escolar, como também para a definição de uma estratégia educativa que considere a melhoria da qualidade de vida das pessoas como o objetivo prioritário a atingir.
\end{abstract}

PALAVRAS-CHAVE:

Educação Artística. Educação Integral. Reforma Educativa. Qualidade.

ABSTRACT - What we talk about when we speak of a quality artistic education: the Chilean case - Developed from a research work for a master's degree in artistic education taught at the Superior School of Education of the Polytechnic Institute of Lisbon, Portugal, the present work seeks to evaluate a publication in support of the National Plan of Arts Education that is being developed in current Chilean educational reform. Used as "classroom material", the analysed notebook has the axes that structure an educational intentionality that seems to us quite pertinent and deserving of study and prominence. As many of the problems of contemporary art education, in particular the lack of clear educational intentions, seem to be transversal to many countries, the work developed in Chile can be a reference not only to justify the presence of arts in the school curriculum, but also for the definition of an educational strategy that considers the improvement of the quality of life of the people as the priority objective to be achieved.

KEY WORDS:

Artistic Education. Integral Education. Educational Reform. Quality.

\section{Introdução}

Na América Latina, dentro do quadro das políticas educativas chilenas, surge para o triênio 2015-2018, o Plano Nacional de Artes na Educação, levado a cabo pelo Conselho da Cultura e das Artes em conjunto com o Ministério de Educação, sob a presidência de Ernesto Ottone Ramirez. Essa ação tem uma peculiaridade relativamente ao que normalmente costuma ser norteador nessas reformas educativas.

Do que falamos quando falamos de uma educação artística de qualidade: o caso chileno.

Revista GEARTE, Porto Alegre, v. 5, n. 2, p. 209-219, maio/ago. 2018.

http://dx.doi.org/10.22456/2357-9854.83958 
Pois a incidência não é apenas no contexto formal (escolas), nem a necessidade de cumprir subidas gerais da educação do país nos hipercompetitivos rankings internacionais de educação, na verdade esse plano tem como objetivo aumentar a intervenção também em contexto não formal, pondo à disposição dos estabelecimentos educacionais, centros culturais e de formação, uma série de cinco cadernos (DURÁN, 2016) que em conjunto vem delinear um conceito de educação artística assente na premissa de que as artes têm a faculdade de melhorar a qualidade de vida das pessoas e das comunidades, tendo em conta que as barreiras de acesso são múltiplas.

Neste sentido a estratégia chilena enfoca-se, não nos produtos materiais e imateriais que a educação artística pode potencialmente gerar no médio ou longo prazo, mas nas pessoas que vão interagir com eles. O caderno orientativo que nos serviu de base a esta reflexão é o número um (Cfr. Referências) de uma coletânea de cinco cadernos. Esse caderno trata então de situar e sublinhar a intencionalidade educativa da iniciativa política, focando especialmente a questão da qualidade e o que a educação artística pode trazer à educação em geral. Os outros cadernos mereceriam também uma análise detalhada que não cabe neste espaço e nos naturais constrangimentos (limite de texto) que condicionam toda e qualquer publicação científica.

\section{Uma arte e uma cultura para quem? Entender a dimensão integral}

O acesso a infraestruturas e a falta de formação artística a impedir a aproximação dos mais desfavorecidos à obra de arte são os pressupostos mais significativos para a necessidade sentida de considerar o acesso às artes e à cultura um direito reconhecido para a sociedade chilena. Diga-se de passagem que esta questão sensível da "acessibilidade" do comum dos cidadãos ao usufruto das produções artísticas e culturais deveria ser algo que deveria preocupar os legisladores políticos de todo o globo. Isto, pensando que vivemos numa era em que a marketização crescente das chamadas indústrias da criatividade e da cultura, valendo atualmente cerca de $3 \%$ do PIB mundial, segundo os relatórios mais recentes (LHERMITTE; BLANC; PERRIN, 2017; McANDREW, 2017), pode perversamente atirar uma significativa parte das pessoas para uma situação de exclusão cultural adicionada à que já vivem enquanto socioexcluídos. Isso porque nem todos têm a possibilidade de aceder 
aos museus, centros culturais, concertos de música e aos mais variados eventos da esfera artística e cultural pela impossibilidade de poder suportar os elevados preços de acesso.

Dentro de um determinado quadro político, esta fixação do campo conceptual da educação artística pretende promover uma educação que seja um contributo para o desenvolvimento integral das pessoas e que promova a fruição da cultura e das artes, gerando assim uma reflexão coletiva sobre o valor e contributo da educação artística na construção de uma educação de qualidade, mais abrangente e que venha assim envolver os docentes e/ou agentes relevantes no processo educativo.

A perspectiva da educação integral defendida do documento em análise chileno encontra-se muito próxima da que é explorada e discutida no Brasil (PINHEIRO; LIBLIK, 2010 e 2014), mas ligeiramente diferente do uso que lhe é dado em Portugal (CHARRÉU, 2015). Os dois termos - "integrada" e "integral" — impulsionam a educação para outros espaços situados fora da arquitetura e dos muros das escolas, buscando-se nos meios urbanos e sociais uma quantidade de coletivos, espaços culturais alternativos e atores culturais underground (rappers, grafitters etc.) agora considerados agentes educativos. Têm a vantagem de "falar" uma linguagem próxima daquilo que circunscreve os problemas e as grandes preocupações da comunidade.

Alguns autores como Castro, Machado e Vitorette (citados por FREITAS et al., 2014, p.167) entendem a educação integral como "uma educação que busca o desenvolvimento integral - ou por inteiro - de todas as potencialidades humanas. Que significa ainda a livre e plena expansão das dimensões intelectuais, afetivas, estéticas e físicas do homem". Aqui se cruza a perspectiva brasileira com a do outro lado do Atlântico preconizada pelo professor Arquimedes da Silva Santos (2003) no que ele chama “a globalização" das expressões (CHARRÉU, 2015).

Considerada, então, fundamental para o desenvolvimento integral das pessoas, a educação artística de qualidade, como algo que permita a fruição das artes e da cultura, é a grande preocupação destes documentos, que visam contribuir para a formação de cidadãos e cidadãs sensíveis à realidade que os rodeia, capazes de respeitar e integrar a diversidade e de estabelecer relações democráticas e \begin{tabular}{ll}
\hline CHARRÉU, Leonardo Verde; GHIRA, Madalena Campos. & 211
\end{tabular} Do que falamos quando falamos de uma educação artística de qualidade: o caso chileno. Revista GEARTE, Porto Alegre, v. 5, n. 2, p. 209-219, maio/ago. 2018. 
participativas. Pretende-se assim dar origem a produtos educativos que permitam às crianças e jovens chilenos exercer o seu direito de aceder de forma igualitária à cultura e às artes.

Além da reflexão coletiva, ilustrada com experiências reais e atividades coletivas dirigidas à aplicação dos conteúdos abordados, esses documentos pretendem também fornecer ferramentas metodológicas e conceptuais para os docentes, num convite à desconstrução de limites entre o estabelecimento educativo e as instituições/parcerias e organizações locais vinculadas à cultura e às artes numa abordagem que visa à desterritorialização de saberes e não a hierarquização e consequente hegemonia de uns sobre os outros, já que o objetivo é gerar linhas de ação conjunta em prol do desenvolvimento de uma educação artística de qualidade.

Segundo a contextualização apresentada no primeiro destes cadernos, considera-se que

uma educação artística e cultural, rica, bem pensada e executada, não só ajuda os estudantes a enriquecer os seus projetos artísticos, motivando-os a usar de forma criativa todos os seus recursos locais e/ou ao seu alcance mas também a formular propostas que vão em benefício do seu desenvolvimento integral (DURÁN, 2016a, p. 11).

Isto, considerando-se então que quando a educação se encontra com as artes e a cultura, abre-se uma via que fornece aos seus receptores, os alunos, a possibilidade de desenvolver todo o seu potencial. Do mesmo modo, fornece aos cidadãos e à própria comunidade novas formas de interagirem com determinadas formas de arte que se integram "relacionalmente" e de forma indelével com as culturas do seu tempo. Será talvez essa dimensão relacional o que inspirou Nicolas Bourriaud na suas teorias sobre estética relacional, levando-o a propor uma ideia de arte atualizada e modificada pelo princípio de intercâmbio no qual:

A possibilidade de uma arte relacional (uma arte que tomaria como horizonte teórico a esfera das interações humanas e seu contexto social, mais que a afirmação de um espaço simbólico autônomo e privado) dá conta de uma mudança radical dos objetivos estéticos, culturais e políticos postos em jogo pela arte moderna. (BOURRIAUD, 2009, p. 19-20). 
Significa que esta esfera das interações humanas, de que nos fala Bourriaud, tomada como horizonte teórico orientador dessa educação artística reformista, teria um valor pelo menos equiparado ao da esfera hegemônica da produção dos artefatos artísticos para posterior apreciação estética. E é precisamente nesse ponto onde se situa uma das importantes diferenças, que ainda fazem sentido hoje, entre a postura utópica e tardo-romântica modernista (da arte pela arte) e a postura pós-modernista de uma arte que interage com a vida das pessoas e das comunidades e que, basicamente, veicula vozes que durante largos momentos da história sempre tiveram em posição de desvantagem.

\section{Operacionalização da dimensão qualitativa da educação artística: problematizações e questões-chave}

Como operacionalizar este plano de ação transversal, envolvendo os agentes que participam nas diferentes etapas é alvo de reflexão dos cadernos que citamos, já a evidenciar um desenho de uma política educativa que prioriza esta definição em torno dos conceito-chave, com o intuito de gerar propostas para a melhor distribuição de recursos, físicos e humanos.

Dentro das ferramentas metodológicas que se encontram disponíveis nesses cadernos, a problematização de questões-chave nesse âmbito, surge em vários momentos do documento em análise, como que a convidar o leitor a refletir, para redimensionar a sua atuação no seu local de trabalho, a "sala de aula", ou aquele espaço que não sendo apenas físico, será onde o conhecimento se processa.

As questões, parecendo óbvias e simples, implicam em um índice de consciencialização e de redirecionamento dos objetivos da educação artística que ultrapassam à mera realização de artefatos artísticos. Assim, o documento, em algumas das suas páginas, assume um formato de indicações para uma espécie de "livro de bordo" para professores e educadores, no qual afloram as questões (DURÁN, 2016a, p. 9):

- Que relação tenho no meu trabalho com a educação artística e cultural de jovens e crianças? 
- O que entendo por uma educação de qualidade?

- Como pode a educação artística contribuir para alcançar uma educação de qualidade?"

Será esta pedagogia da pergunta uma ferramenta metodológica na reflexão que se pretende, gerando a cumplicidade necessária para quem lê, sendo assim também parte integrante do processo.

\section{Um olhar para as recomendações internacionais: gerando novas questões}

Nos últimos anos tem-se produzido em nível internacional uma mudança de enfoque sobre o tema da educação dirigido à conquista de territórios alargados que querem considerar a qualidade e a equidade como conceitos indissociáveis, seguindo de perto as metas da UNESCO (2000) que visam ao desenvolvimento de uma educação integradora, cimentada em quatro pilares: ser, conhecer, fazer e conviver. Considera-se, no entanto, neste documento, que essas metas ainda assentes nos resultados acadêmicos medíveis em provas estandartizadas carecem de novos olhares que deixam crer que a educação implica muitos outros âmbitos. Segundo o Sistema Nacional de Assessoria da Qualidade na Educação chileno, a escola também deve garantir aspetos relacionados com a auto-estima, a convivência escolar, os hábitos de vida saudável, a igualdade de gênero e a motivação escolar.

É nesse contexto que a educação artística, a par com a educação física, a formação técnica e a educação para a cidadania, surgem como as chaves para o favorecimento de processos que integrem distintos âmbitos de conhecimento e que potenciem a autodescoberta, pelo que importará refletir em mais algumas questões orientadoras para a boa implementação destas práticas contidas no caderno em análise (DURÁN, 2016, p. 13):

- Que práticas artísticas não contribuem para uma educação de qualidade?

- Como se podem modificar para melhorar?

- Que elementos na nossa prática contribuem sim para uma educação de qualidade? 
No quadro de referência internacional, o mesmo documento da UNESCO (2000), considera o domínio da Cultura e das Artes necessário para formação das pessoas, enquadrando o seu território de aprendizagem, quando incluídas diferentes manifestações criativas, um campo de desenvolvimento integral e autônomo das pessoas com a sua própria experiência:

- Quando acompanhada de reflexão promove pensamento abstrato e divergente e permite buscas de soluções criativas;

- Favorece o desenvolvimento de habilidades artísticas e qualidades como a sensibilidade e tolerância;

- Contribui para o desenvolvimento de valores;

- Promove o conhecimento da própria identidade e aproxima culturas;

- Tem caráter terapêutico.

Também no quadro de referência local as evidências dos benefícios da educação artística e cultural têm expressão em estudos que demonstram o favorecimento ao nível do desenvolvimento individual quando em contato com a arte e a cultura e mais uma vez as questões surgem pertinentes e sugestivas da relação tempo-qualidade vs teoria-reflexão, ou seja, a necessidade de parar e refletir, questionando e/ou problematizando o que se apresenta como algo enraizado e/ou cristalizado, para que novas linhas de ação e pensamento possam surgir.

- Que importância tem a educação artística na instituição onde trabalha?

- É relevante para a formação das crianças e jovens?"

- Na sua instituição promove-se uma educação de qualidade? Se sim, por quê? Se não, o que podia fazer para melhorar?"

Estas questões, por parecerem óbvias e até ingênuas e com uma familiaridade tão evidente, tendemos a naturalizá-las e a não Ihes dar a importância que merecem. São no entanto fundamentais em processos de mudança e inovação, sobretudo quando em muitos lugares de aprendizagem, formais e informais, chegamos até aquele momento em que temos a sensação de um déjá vu desmotivante para todos os envolvidos, professores, alunos e comunidade envolvente. Referimo-nos às 
mesmas festas (essa tentação de instrumentalizar a educação artística como aquela área que serve para decorar a escola em ocasiões especiais), aos mesmo trabalhos expostos, às mesmas rotinas que tolhem a criatividade e levam ao desinteresse e desmotivação da comunidade educativa.

\section{Que premissas devemos então adotar para uma educação artística de qualidade?}

Para atingir o objetivo de uma educação artística de qualidade, disponível para todos, apenas a existência de atividades relacionadas com a arte e a cultura, não é suficiente, requerem-se também condições e boas decisões para que os estudantes tenham a possibilidade de aceder a experiências artísticas motivadoras e significativas para o seu desenvolvimento. No estudo realizado pela Fundação Wallace, o famoso Project Zero da Universidade de Harvard, são apresentadas ações para alcançar esta meta (SEIDEL, 2009) que são tomadas a vários níveis:

Ao nível da Reflexão e Diálogo - para definir o conceito de qualidade, todos os envolvidos no processo de aprendizagem artística são chamados à responsabilidade no que concerne às decisões tomadas quanto à atividade formativa, tendo em conta que as decisões terão um impacto no desenvolvimento e não apenas na aprendizagem.

Ao nível das Múltiplas Perspectivas - para guiar a reflexão e o diálogo sobre a qualidade em educação artística é necessário o diagnóstico a partir de quatro perspectivas distintas: aprendizagem (conhecimentos a adquirir), pedagogia (intencionalidade educativa), comunidade (relações sociais dentro e fora da sala), meio ambiente (espaço físico, materiais e tempo destinado às artes).

Ao nível das Decisões sobre o Programa - há quatro perguntas básicas para definir os programas de educação artística: i) quem ensina as artes ; li) quando se ensinam as artes; lii) O que se ensina e como; iv) Como se avaliam as aprendizagens artísticas.

Por fim, ao nível dos Responsáveis pela tomada de decisões - a qualidade em educação artística depende das pessoas que tomam decisões, por mínimas que sejam, a todos os níveis, desde quem elabora as políticas públicas (criação de currículos e 
sistemas para medir a qualidade em educação, exigências de qualidade para a formação de docentes e acesso ao aperfeiçoamento); quem financia a educação artística (Ministério da Educação, Municípios, outros); Instituições (equipes/direção de serviços culturais, museus, teatros, galerias, bibliotecas, etc.) e inclusivamente ao nível da aula, o programa (docentes, artistas).

Vimos, acima, as ações e os contextos em que devem ser tomadas, a seguir elencamos um conjunto de caraterísticas que conformam uma educação artística de qualidade, podendo até servir de indicadores avaliativos. Então, uma educação artística de qualidade caracteriza-se por oito itens:

- Recursos - respeitantes a infraestruturas, tempos e materiais;

- Relevância - que leva entender a educação artística como um campo que possibilita o desenvolvimento humano e comunitário;

- Colaboração - que implica o desenvolvimento de processos criativos que normalmente são transformados em experiências significativas;

- Territorialidade - que envolve o estabelecimento de vínculos com a comunidade;

- Reflexão - que requer e promove o pensamento crítico e reflexivo, evitando a repetição e cópia;

- Pertinência - que exige o desenvolvimento de um sentido de identidade/multiculturalidade.

- Multidisciplinaridade - que requer uma metodologia de projeto que pode envolver a transversalidade disciplinar;

- Avaliação - que poderá envolver vários tipos de avaliação que podem ir da avaliação formativa à avaliação dos processos, entre outras modalidades de avaliação.

Ultrapassando o que normalmente se passa na solidão da profissão docente, ou do animador cultural que, em regra, tendem a seguir um guião determinado pelas origens acadêmicas (área de conforto acadêmico), essas premissas e orientações exigem, claramente, um tipo de docente e docência que já não pode assentar sobre um modelo expositivo e de supostas verdades estéticas validadas pelas vetustas disciplinas artísticas que há que impor sobre um público ignorante e insensível. Pensar 
na qualidade em educação artística é pensar numa complexidade que, como vimos acima, vai mais além de uma mera prática de transmissão de conteúdos.

\section{Conclusões}

Neste texto procuramos sintetizar o que poderiam ser orientações curriculares e didático-pedagógicas para a área da educação artística a aplicar em sistemas de ensino cujos usuários (alunos, professores e comunidade) reclamem por mudança. Consideramos significativo que a fonte básica para a nossa análise tenha sido produzido por um país, em regra, fora do foco das grandes potências culturais (que se confundem com as potências econômicas) que costumam servir de referência para as reformas educativas levadas a cabo em todo o mundo.

O documento-base (DURÁN, 2016a) que estudamos não nos pareceu, em momento algum, presunçoso, apesar de uma espécie de intencionalidade prescritiva visível em algumas das suas partes, que se impõe sobre uma desejável intencionalidade propositiva. Sublinhamos a simplicidade das perguntas, que são corajosas, quando as exigências intelectuais do mundo da educação tendem a deslizar as suas metanarrativas justificativas para as complexidades das filosofias contemporâneas eurocêntricas para justificar reformas e mudanças. Esse regresso às perguntas primordiais, simples e diretas, (que muitos de nós já tínhamos esquecido) tem o condão de nos forçar a pensar de novo, a partir das bases, no intuito de lograrmos uma educação artística de qualidade. Quem gosta do que faz, sabe que, de tempos em tempos, deve responder a essas perguntas e rever, nas respostas, a qualidade do seu próprio trabalho docente.

\section{Referências}

BOURRIAUD, Nicolas. Estética Relacional. São Paulo: Martins Fontes, 2009.

CHARRÉU, Leonardo. Em busca de fontes, autores e fatos singulares da história da integração das expressões artísticas na educação: a contribuição de Arquimedes da Silva Santos em Portugal. In PINHEIRO, Marta; LIBLIK, Ana (Orgs.) Educação integral e integrada: subsídios para a formação de professores. Curitiba: UFPR/Setor de Educação, 2015. p. 37-60.

DURÁN, Pablo (Coord.). Cuaderno 1 El aporte de las artes y la cultura a una educación de calidad: caja de herramientas de educación artística. Santiago do Chile: Consejo National de la Cultura y las Artes, 2016a.

DURÁN, Pablo (Coord.). Cuaderno 2 Por qué enseñar artes y como hacerlo: caja de herramientas de educación artística. Santiago do Chile: Consejo National de la Cultura y las Artes, $2016 \mathrm{~b}$. 
DURÁN, Pablo (Coord.). Cuaderno 3 Una educación artística en diálogo con otras disciplinas: caja de herramientas de educación artística. Santiago do Chile: Consejo National de la Cultura y las Artes, 2016c.

DURÁN, Pablo (Coord.). Cuaderno 4 Educación artística para la formación ciudadana: caja de herramientas de educación artística. Santiago do Chile: Consejo National de la Cultura y las Artes, 2016d.

DURÁN, Pablo (Coord.). Cuaderno 5 Educación artística y diversidad cultural: caja de herramientas de educación artística. Santiago do Chile: Consejo National de la Cultura y las Artes, 2016e.

FREITAS, Maria de Fátima et. al. As dimensões pedagógicas do trabalho em cooperativa na perspectiva da educação integral, In: PINHEIRO, Marta e LIBLIK, Ana Maria. (Orgs). Educação Integral e Integrada contribuições da Universidade Federal do Paraná. Curitiba/ Setor da Educação, 2014, p. 147-171.

LHERMITTE, Marc; BLANC, Solenne; PERRIN, Bruno. (Coords.). Cultural Times. The first global map of cultural and creative industries. S/L: CISAC, 2015

McANDREW, Clare. The art market 2017. An Art Basel \& UBS Report. Basileia: Art Basel \& UBS, 2017.

PINHEIRO, Marta; LIBLIK, Ana. (Orgs.) Educação integral e integrada: no contexto da educação a distância. 2 ed. Curitiba/ Setor da Educação, 2010.

PINHEIRO, Marta; LIBLIK, Ana. (Orgs.) Educação integral e integrada: contribuições da Universidade Federal do Paraná. Curitiba/ Setor da Educação, 2014.

SANTOS, Arquimedes da Silva. Mediações arte-educacionais, ensaios coligidos. Lisboa: Fundação Calouste Gulbenkian, 2008.

SEIDEL, Steve et al. The Qualities of Quality, Understanding Excellence in Arts Education. Cambridge, MA: Wallace Foundation, 2009. Disponível em: http://www.wallacefoundation.org/knowledge- center/artseducation/arts-classroom-instruction/ Documents/Understanding-Excellence-in-Arts-Education.pdf . Acesso em 12 maio 2018.

UNESCO. Marco de acción de Dakar. Educación para todos: cumplir nuestros compromisos comunes. París: Unesco, 2000. Disponível em http://unesdoc.unesco.org/images/0012/001211/121147s.pdf. Acesso em 12/ maio 2018.

\section{Leonardo Verde Charréu}

Professor na Escola Superior de Educação (ESELX) do Instituto Politécnico de Lisboa (IPL), Portugal. Investigador do CIED (Centro Interdisciplinar de Estudos Educacionais ESELX/IPL), no CIEBA (Centro de Estudos e Pesquisas em Belas Artes, FBAUL/UL) e no GEPAEC (Grupo de Estudos e Pesquisas em Arte, Educação e Cultura, UFSM).

E-mail: leonardo.charreu@gmail.com

Currículo: http://charreu9.wixsite.com/arts

\section{Madalena Campos Ghira}

Frequentou a licenciatura em Pintura, Faculdade de Belas Artes do Porto e Design de Comunicação, Faculdade de Belas Artes de Lisboa. Tem Pós-Graduação em Livro Infantil pela Universidade Católica de Lisboa. Leciona as disciplinas de expressão artística na Escola Profissional Val do Rio, onde assume também cargos de assessoria e coordenação artística, levando a cabo projetos transdisciplinares que se constituem agora como objeto da sua investigação no Mestrado em Educação Artística.

E-mail: madalena.ghira@gmail.com

Currículo: 